\title{
Transient Radiation Darkening Features in VISAR Window Materials
}

June 2001 


\title{
DISCLAIMER
}

This report was prepared as an account of work sponsored by an agency of the United States Government. Neither the United States Government nor any agency thereof, nor any of their employees, nor any of their contractors, subcontractors or their employees, makes any warranty, express or implied, or assumes any legal liability or responsibility for the accuracy, completeness, or any third party.s use or the results of such use of any information, apparatus, product, or process disclosed, or represents that its use would not infringe privately owned rights. Reference herein to any specific commercial product, process, or service by trade name, trademark, manufacturer, or otherwise, does not necessarily constitute or imply its endorsement, recommendation, or favoring by the United States Government or any agency thereof or its contractors or subcontractors. The views and opinions of authors expressed herein do not necessarily state or reflect those of the United States Government or any agency thereof.

Available to the public from:

\author{
U.S. Department of Commerce \\ National Technical Information Service \\ 5285 Port Royal Road \\ Springfield, VA 22161 \\ (703) 487-4650
}

Available electronically at http://www.doe.gov/bridge. Available to U.S. Department of Energy and its contractors in paper from:

U.S. Department of Energy

Office of Scientific and Technical Information

P.O. Box 62

Oak Ridge, TN 37831-0062

(423) 576-8401 


\title{
Transient Radiation Darkening Features in VISAR Window
}

\author{
June 2001
}

Gerald Stevens

Kenneth Moy

This work was supported by the U.S. Department of Energy, National Nuclear Security Administration Nevada Operations Office, under Contract No. DE-AC08-96NV11718. 


\section{CONTENTS}

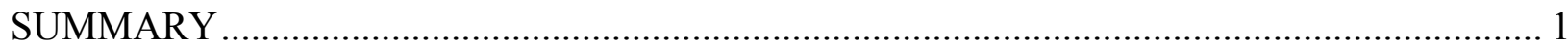

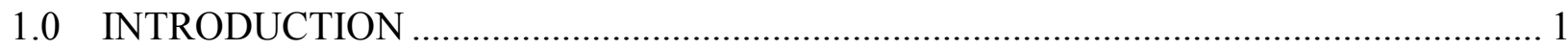

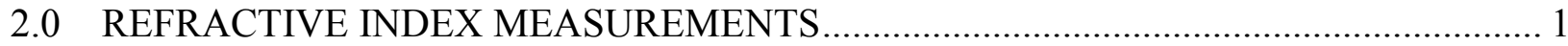

2.1 Experimental Configuration........................................................................... 1

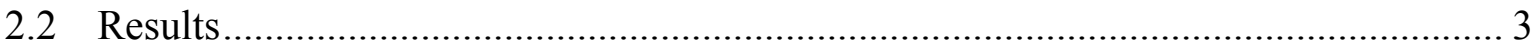

2.2.1 Lithium Fluoride (LiF) ......................................................................... 3

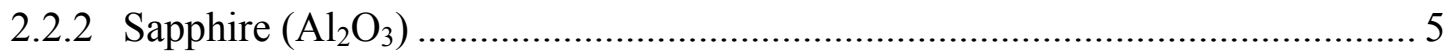

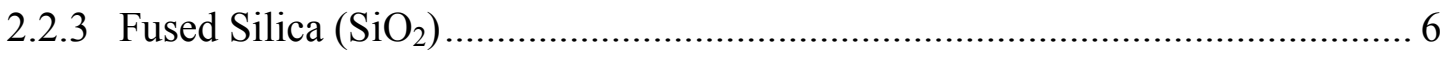

2.3 Thermal Change in Index.................................................................................. 8

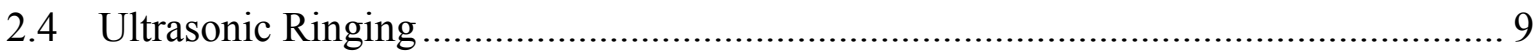

3.0 SPECTRALLY AND TEMPORALLY RESOLVED TRD............................................ 9

3.1 Discussion of Spectral Streak Results, Color Center, and Colloid Formation ........... 13

3.1.1 Lithium Fluoride (LiF) ............................................................................ 13

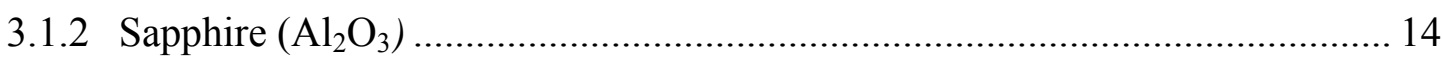

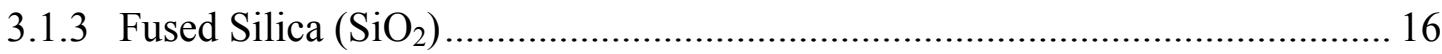

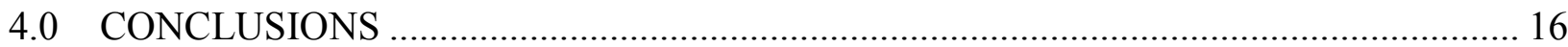

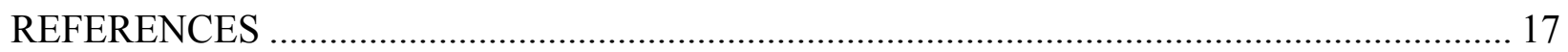




\section{SUMMARY}

We have studied and characterized radiation-induced changes in the index of refraction of materials used in $\mathrm{Z}$ experiments. Interferometric measurements of the radiation-induced change in the real part, $n$, of the complex index of refraction, $N=n+i K$, have been made in lithium fluoride (LiF), sapphire, and fused silica samples. Our results indicate that the index changes are small, with $\delta \mathrm{n} / \mathrm{n} \sim 1 \cdot 10^{-5} / \mathrm{kGy}$. In addition, we have characterized the dose dependence of the radiation-induced transient radiation darkening (TRD) of these materials, which is related to $K$, the imaginary part of the refractive index. We have also measured time-resolved spectral profiles of TRD in LiF and sapphire, and have examined the results in terms of known color centers and possible colloid aggregation. 


\subsection{INTRODUCTION}

Many equation of state experiments at $\mathrm{Z}$ make use of the pinch radiation to produce shock waves in materials. Unfortunately, the radiation also adversely affects the diagnostic systems that are fielded in close proximity to the pinch region. This environment may cause measurable changes in the optical properties of materials, which may be described by a change in the complex index of refraction, $N=n+i K$. A change in $n$ results in a change in the effective optical path length, while a change in $K$ results in attenuation of the transmitted light. These radiation-induced effects limit the dynamic range of experiments and introduce systematic uncertainties to VISAR velocity data. An understanding of the radiation effects in optical components may help limit VISAR measurement uncertainty and lead to more precise experimental data at $\mathrm{Z}$.

An experimental program was undertaken at Special Technologies Laboratory (STL) to study the radiation-induced effects in optical windows and components using a Febetron 705 pulsed radiation source. The Febetron provides high dose levels (hundreds of krads) of energetic electrons (up to $2.5 \mathrm{MeV}$ ) in very short times ( $\sim 30 \mathrm{~ns}$ ), and is capable of darkening windows to levels comparable to those observed at $\mathrm{Z}$.

Last year Sandia National Laboratories (SNL) began using magnetic field pressure to isentropically compress materials in the so-called "ICE" configuration at Z. With the shift to these experimental configurations, the radiation environment is reduced drastically, and darkening/index changes in windows are no longer a significant concern. However, for pinchradiation-based experiments at $Z$, the measurement uncertainties in optically-based systems due to radiation induced effects can be estimated from these STL test results.

\subsection{REFRACTIVE INDEX MEASUREMENTS}

\subsection{Experimental Configuration}

A Febetron 705 was used to provide radiation pulses to selected test-samples. In these tests, the Febetron Marx-bank capacitors were charged to $32 \mathrm{kV}$, corresponding to an electron endpoint energy of approximately $2.2 \mathrm{MeV}$. To vary the incident radiation dose and to smooth the electron beam's spatial profile, $25.4-\mu \mathrm{m}$-thick Al scattering foils were placed $3 \mathrm{~cm}$ before the sample, which was located about $25 \mathrm{~cm}$ downstream from the Febetron emission window. Dosimetry was performed using Far West Technologies radiachromic film $\left(1 \mathrm{~cm}^{2}\right.$ x $43.5 \mu \mathrm{m}$ thick). A Faraday cup was used to monitor the time profile of the pulse.

We used a Mach-Zehnder (M-Z) interferometer to measure the radiation-induced change in optical path length for each sample. Light from a 542-nm He-Ne laser $\left(\mathrm{P}_{\mathrm{cw}} \sim 1 \mathrm{~mW}\right)$ is transported into the Febetron room via a $50-\mu \mathrm{m}$-diameter-core multimode fiber. The fiber is shielded from stray radiation by $5 \mathrm{~cm}$ thick lead bricks. The laser light is expanded and collimated by a $10 \mathrm{X}$ microscope objective lens before entering the interferometer. Light from the interferometer's complementary outputs is collected by similar fiber / microscope objective couplers, and is sent to two Newport model 1801 optical receivers located in a screen room. The receivers have a bandwidth of $125 \mathrm{MHz}$ and a maximum conversion gain of $2 \times 10^{4} \mathrm{~V} / \mathrm{W}$. Signals are recorded on LeCroy 9450 oscilloscopes at a sampling rate of $4 \times 10^{8} \mathrm{~s}^{-1}$. The net bandwidth of the system is sufficiently high to give us the desired temporal resolution to resolve a Febetron radiation pulse. A schematic of the interferometer in the test configuration is shown in Figure 1. 


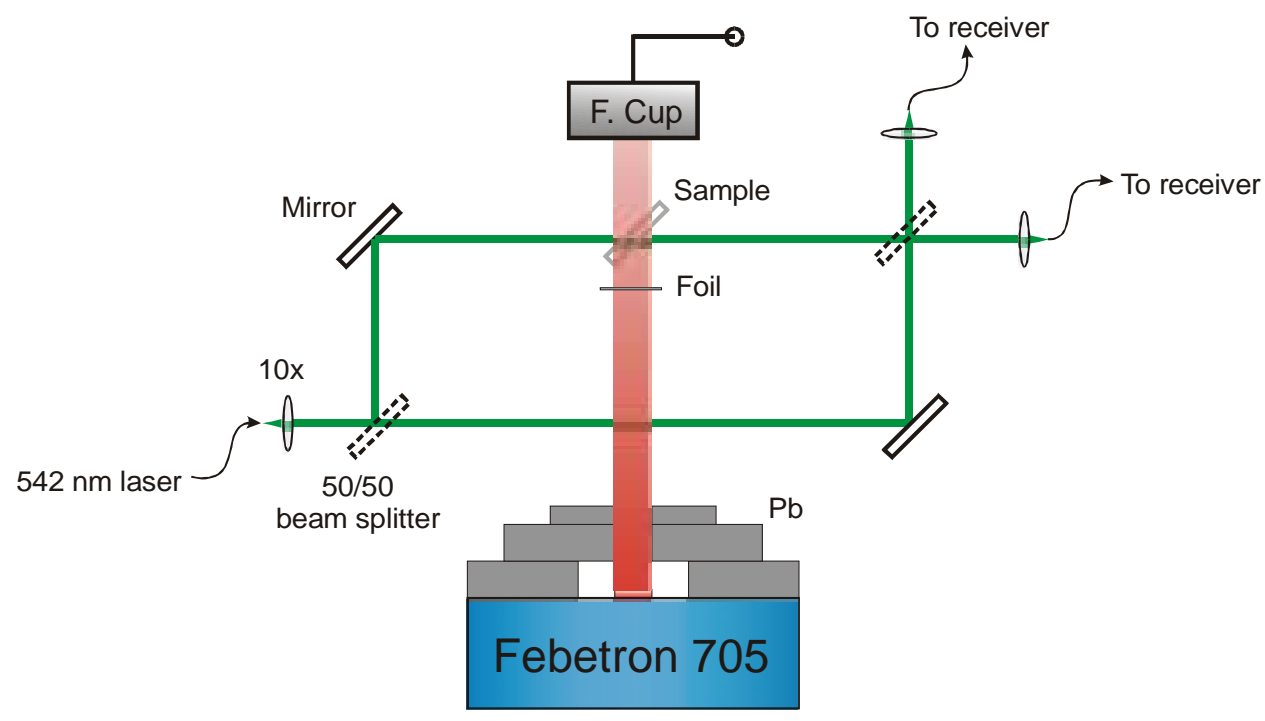

Figure 1. Schematic of Febetron/M-Z interferometer setup.

By placing the test sample in one leg of the interferometer, we introduce an effective path length difference between the two legs. If the index of refraction of the sample window changes due to irradiation, so does the effective optical path length through the window, resulting in a shift in the interferometric fringes. The two output signals of the interferometer are $180^{\circ}$ out of phase, and have time dependencies that may be modeled by:

$$
\mathrm{S}_{1}(\mathrm{t})=\mathrm{A}(\mathrm{t}) \cdot \sin ^{2}(\theta(\mathrm{t}) / 2) \quad \mathrm{S}_{2}(\mathrm{t})=\mathrm{A}(\mathrm{t}) \cdot \cos ^{2}(\theta(\mathrm{t}) / 2)
$$

where $A(t)$ is the time dependent light intensity, and $\theta(t)$ is the phase of the interference fringes. These two parameters are related to the real and complex indices of refraction $n$ and $K$ by:

$$
\mathrm{A}(\mathrm{t})=\mathrm{A}_{\mathrm{o}} \mathrm{e}^{-[2 \pi \mathrm{K}(\mathrm{t}) \cdot \mathrm{d} / \lambda]} \quad \Delta \theta(\mathrm{t})=360^{\circ} \cdot \Delta \mathrm{n}(\mathrm{t}) \cdot \mathrm{d} / \lambda
$$

where $d$ is the window thickness. We record the interference pattern for each of the complementary outputs of the $\mathrm{M}-\mathrm{Z}$ interferometer during a radiation pulse to extract both $\mathrm{A}(\mathrm{t})$, and $\theta(t)$ for a given radiation dose. Very slight darkening of the fibers due to incomplete radiation shielding has been observed and is at worst about a $2 \%$ loss of transmission. In most cases this is substantially less than the darkening observed in the sample material.

Interferometric fringes were acquired prior to each radiation pulse and used to normalize each data set. Total extinction of the light at each output was not obtainable, due to multi-mode fiber speckle, lack of polarization, misalignment, and a slightly radiation damaged beam-splitter. Fringe offsets and amplitudes were determined by kicking one of the mirrors with a bi-morph piezo transducer (PZT) and recording the resulting fringe patterns.

We measured sample transmittance during a radiation pulse with one leg of the interferometer blocked, in order to obtain a better signal-to-noise ratio. 


\subsection{Results}

\subsubsection{Lithium Fluoride (LiF)}

Using a 12.7- $\mathrm{mm}$ diameter by $1.0-\mathrm{mm}$-thick $\mathrm{LiF}$ window purchased from Bicron, we recorded the radiation induced index change for several different doses. Figure 2 shows a typical normalized set of M-Z signals for a dose of about $350 \mathrm{krad}$, with the pulse occurring approximately $1.5 \mu \mathrm{sec}$ into the scan. The radiation pulse causes a prompt phase change in the interferometer signals, which is followed by acoustic ringing.

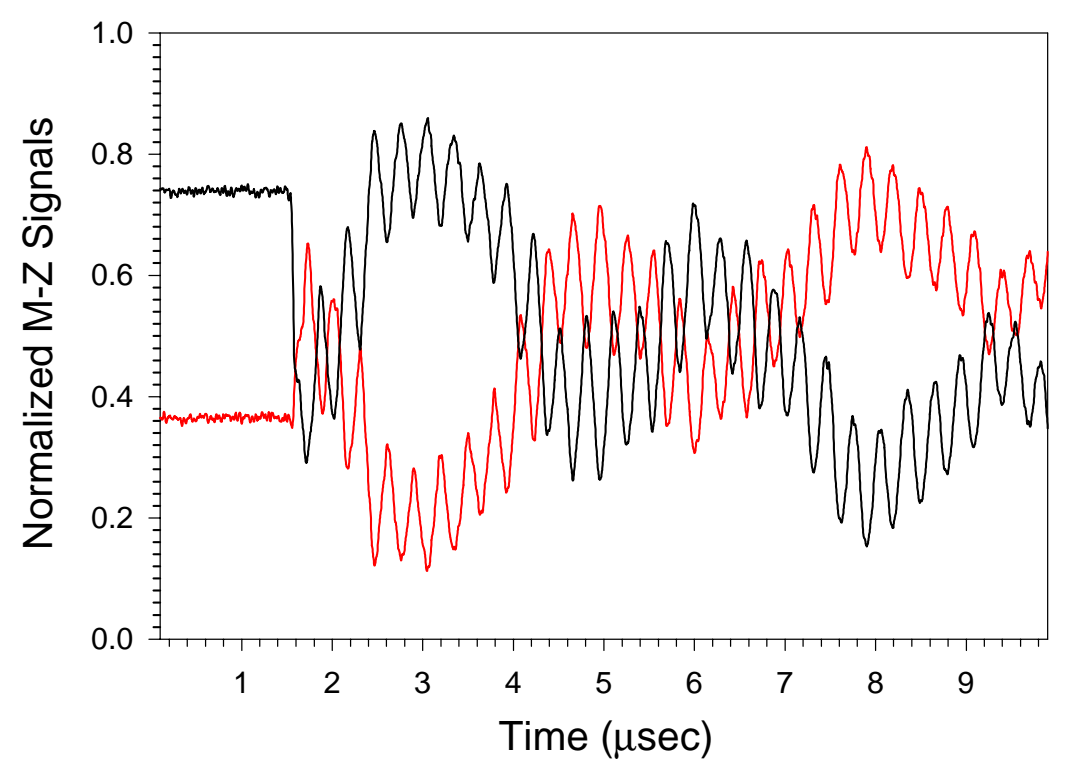

Figure 2. Complementary signals from the $\mathrm{M}-\mathrm{Z}$ inteferometer exhibiting the initial phase change, and thermo-acoustic ringing.

To estimate the effect produced by a change of index in a VISAR window, consider for example the data obtained for an absorbed dose of 490(60) krad. At this high level of irradiation, we observed a change in phase of $\Delta \theta=33(2)$ degrees. Differentiating $\theta(t)$ allows us to make an estimate of the effective velocity error in a VISAR measurement subject to TRD. This velocity is given by

$$
U_{\text {eff }}=(\lambda / 2 \pi)(d \theta / d t)_{\max }
$$

Using the radiation pulse width of $\sim 30 \mathrm{~ns},(\mathrm{~d} \theta / \mathrm{dt})_{\max }=1.1(1)^{\circ} / \mathrm{ns}$, and thus $U_{\text {eff }}=1.5(1) \mathrm{m} / \mathrm{s}$. This is typically beneath the resolution for most VISAR measurements at $Z$, where the system is optimized to measure velocities on the order of $\mathrm{km} / \mathrm{s}$. It is also a small effect when compared with the typical $28 \%$ velocity correction due to the pressure-induced increase in the index of refraction for LiF VISAR windows. This index change is a weak function of pressure and particle velocity for typical shock experiments, only varying from $26 \%$ to $28.5 \%$ for particle velocities that range from 0.1 to $2.5 \mathrm{~km} / \mathrm{s}$. For example, a VISAR measured interface velocity of $1.0 \mathrm{~km} / \mathrm{s}$ made through a $\mathrm{LiF}$ window is about $28 \%$ higher than the actual interface velocity, and a correction of $-280 \mathrm{~m} / \mathrm{s}$ needs to be applied. 
Figure 3 shows the single-pulse radiation-induced absorption of 542-nm laser light versus dose for a 2.0-mm-thick sample of LiF. Attenuation was measured at the point of maximum darkening. The figure shows saturation behavior, with a maximum absorption of about $29 \%$. The absorption has a 1/e saturation point at about 220(20) krad.

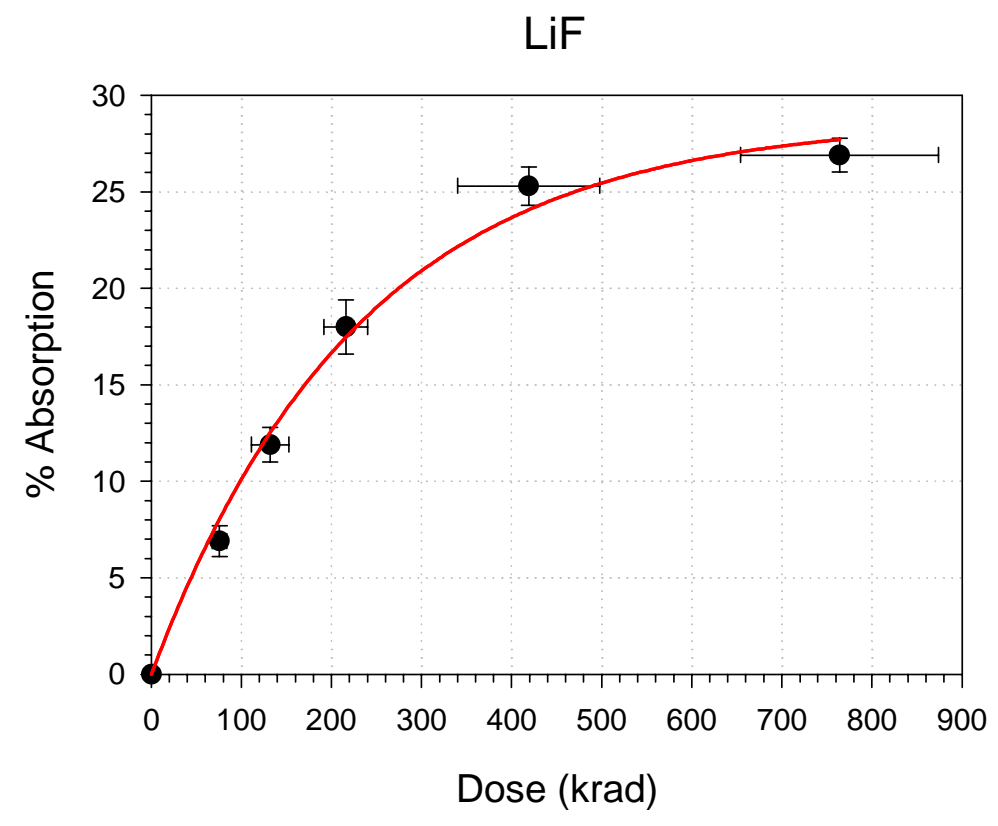

Figure 3. TRD versus dose for a $2.0 \mathrm{~mm} \mathrm{LiF} \mathrm{sample.}$

Using a Beckman spectrophotometer, we observed the post-irradiation absorption spectrum of color centers for a heavily irradiated ( $>500 \mathrm{krad})$ sample.

Figure 4 shows the long term transmission spectrum, which exhibits absorption bands of the three prominent color centers; the $F$-center at $250 \mathrm{~nm}$, the broad $F_{2}{ }^{+}$-center at $625 \mathrm{~nm}$, and the $F_{2}$-center at $444 \mathrm{~nm}$. An $F$-center is an anion (a fluorine ion in $\mathrm{LiF}$ ) vacancy that has trapped an electron. The $F_{2}{ }^{+}$-centers consist of two anion vacancies with one shared, bound electron. These color centers are photo-conductive, and they slowly (over several hours) convert to $F_{2}$ - centers by the process ${ }^{1} F_{2}{ }^{+}+F_{2}{ }^{-} \rightarrow 2 F_{2}$. This process may be measured (Figure 4 ), and may also be observed by eye, as a heavily irradiated sample quickly turns light blue after irradiation, and over the next 24 hours turns yellow. Lisitsyna wrote a thorough summary ${ }^{2}$ of the many processes that contribute to the formation of complex color centers in $\mathrm{LiF}$, to which the reader is referred.

The absorption wavelengths for all of the observed color centers are somewhat distant from the 542-nm wavelength of our probe laser, and it is not altogether obvious what role each color center plays in the TRD phenomena. In order to better characterize the contribution of the various color centers to TRD, we set up a system to make time-resolved spectral measurements. This is described in section 3 . 


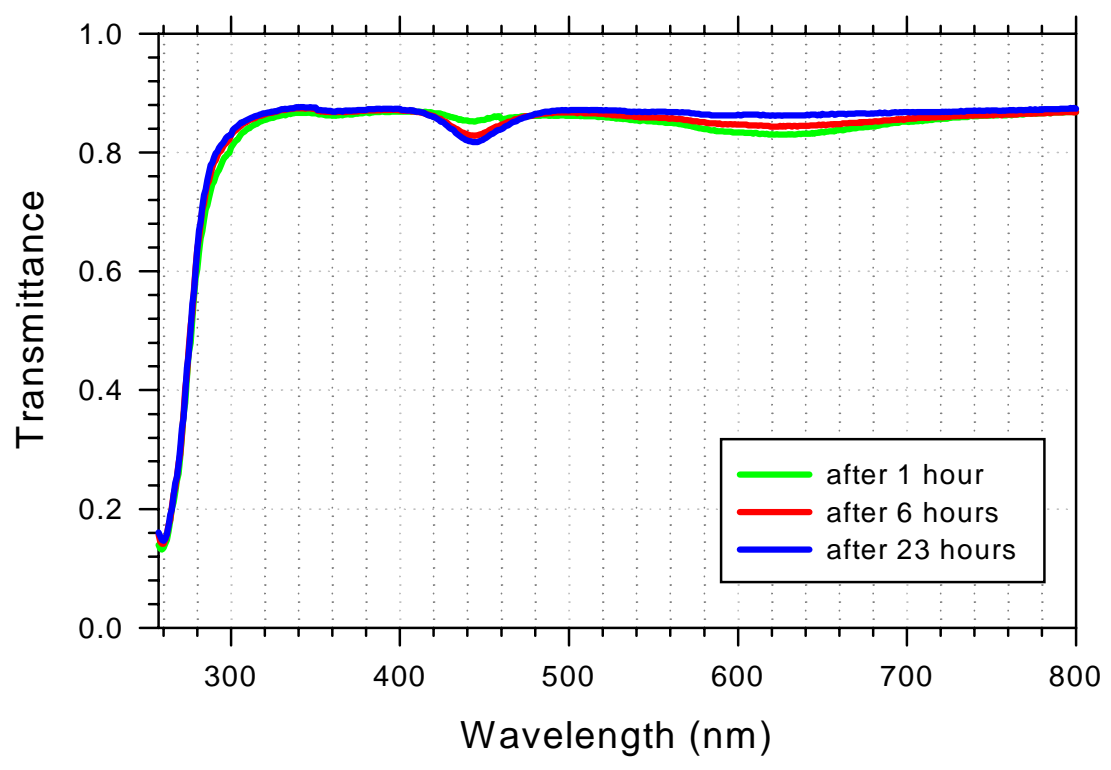

Figure 4. Transmission spectrum of previously irradiated $\mathrm{LiF}$ for various times after irradiation.

We found that absorbed doses of $500 \mathrm{krad}$ and higher could cause physical damage to LiF windows, and in one case a large dose shattered the sample. In another experiment, a thick sample of LiF that was repeatedly subjected to large doses exhibited striations along the surfaces, as well as pronounced surface curvature. Depending on the radiation environment at Z, such damage could affect the results of a VISAR measurement.

Figure 5 shows the measured phase change in a M-Z interferometer when a 1.0-mm-thick sample of $\mathrm{LiF}$ is irradiated in one leg. It appears to be linear, with a slope of $0.074(4)^{\circ} / \mathrm{krad}$. A discussion of these results follows in section 2.3.

\subsubsection{Sapphire $\left(\mathrm{Al}_{2} \mathrm{O}_{3}\right)$}

Measurements of the transient effects of radiation on sapphire crystals are complicated by the birefringence of the crystal. Polarization-dependent radiation-induced retardation of the probe laser light transmitted through the window causes the $\mathrm{M}-\mathrm{Z}$ interferometer outputs to lose their complementary nature. Often, the absorption signal extracted from interferometric measurements shows artificial oscillations due to birefringence effects. In order to minimize these effects, we first polarized the input light to be parallel to the mirror faces. Next, we placed a second polarizer just after the sample with its polarization perpendicular to that of the incident light. One of the sample axes was then oriented parallel to the incident light, in order to minimize rotation of the incident polarization. Next, the polarizer after the sample was removed. Using the interferometer in this configuration we observed a $\Delta \theta$ of about $27^{\circ}$ for an incident dose of 440(40) krad. Due to the difficulties produced by polarization effects, we were unable to perform a complete characterization of the radiation-induced change in refractive index of sapphire. 


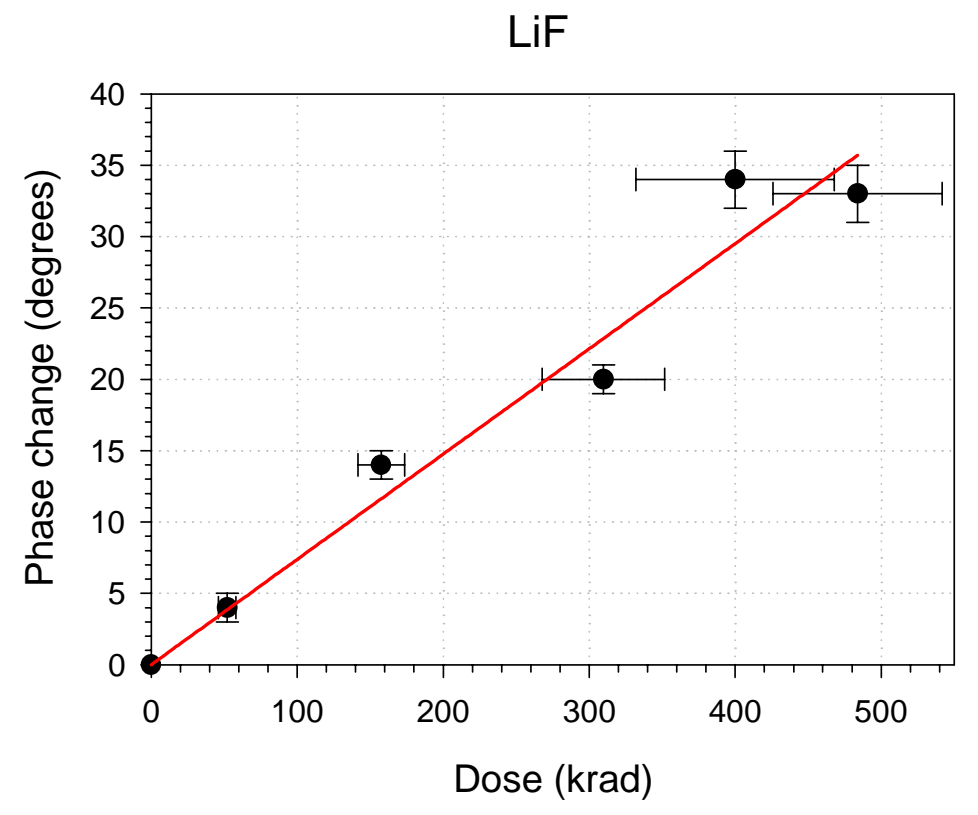

Figure 5. Change in phase versus dose for a $1.0 \mathrm{~mm} \mathrm{LiF} \mathrm{sample.}$

In order to investigate the saturation behavior of TRD in sapphire, we once again dismantled the interferometer and set up a straight path for the light to pass through the sample and into a receiver. Figure 6 shows absorption versus dose for a 1.0-mm-thick sapphire sample. It shows evidence of saturation at lower doses than for $\mathrm{LiF}$. The maximum observed absorption in sapphire is about $18 \%$, with a $1 /$ e point at $90(20) \mathrm{krad}$.

\subsubsection{Fused Silica $\left(\mathrm{SiO}_{2}\right)$}

Fused silica is extremely rad-hard, and we have had trouble seeing thin samples darken even at doses larger than $500 \mathrm{krad}$. This may seem contrary to work that has been reported for fibers, where fibers are seen to darken significantly at doses lower than this. However, we are working with material lengths of $1.0 \mathrm{~mm}$, while fiber lengths may be anywhere from $100 \mathrm{~mm}$ to many meters. STL TRD measurements for high-purity fused silica fibers give a peak absorption constant of $0.3 \mathrm{~dB} /(\mathrm{krad} \cdot \mathrm{m})$ for a $500 \mathrm{krad}$ pulse. For a $1.0-\mathrm{mm}$-thick window, we would expect to see about $0.15 \mathrm{~dB}(3 \%)$ reduction in transmission. However, due to our limited $\mathrm{S} / \mathrm{N}$, a large Cerenkov signal, and background fiber darkening, quantitative measurements of such small changes in transmission are not possible. The phase change due to the radiation pulse is however quite pronounced. Also, the phase change is not obscured by the acoustic ringing present in the measurements on the other window samples. Figure 7 shows the phase change versus dose for a $1.0-\mathrm{mm}$-thick sample. It appears to be linear, with a slope of $0.072(3)^{\circ} / \mathrm{krad}$. 


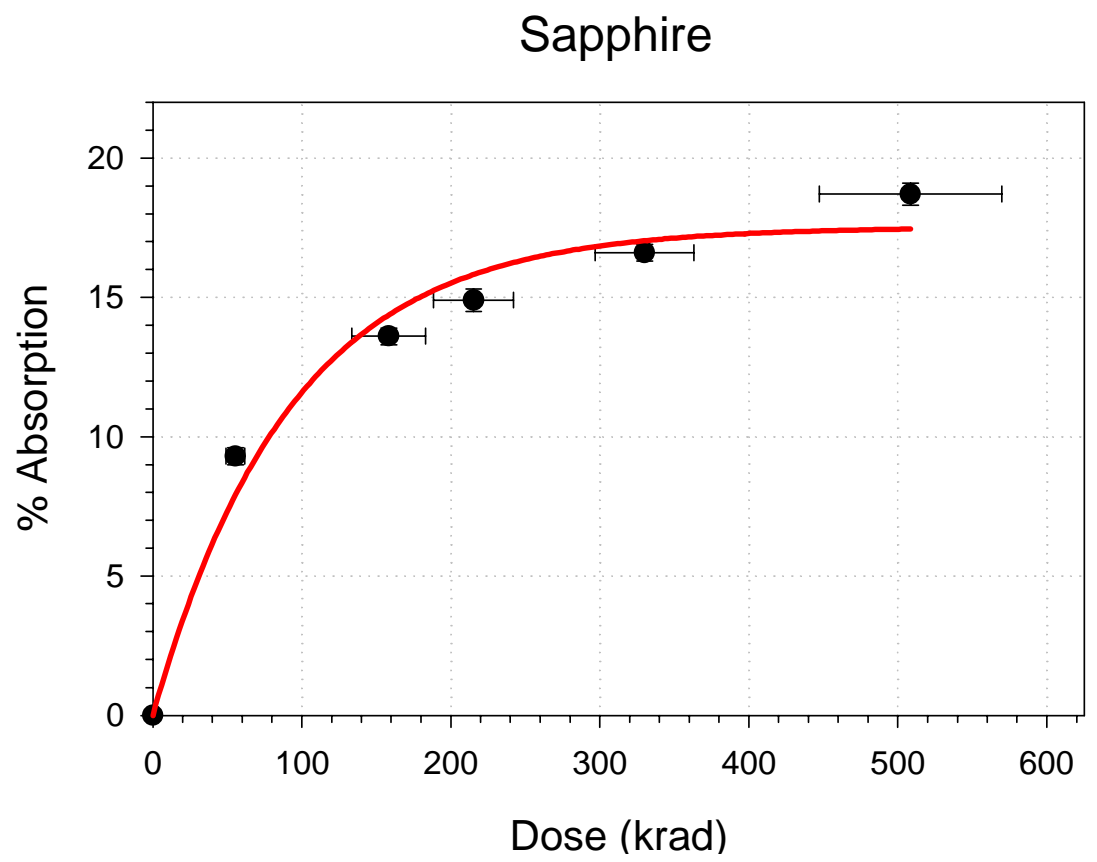

Figure 6. Peak transient absorption versus dose for a $1.0 \mathrm{~mm}$ sapphire sample.

\section{Fused Silica}

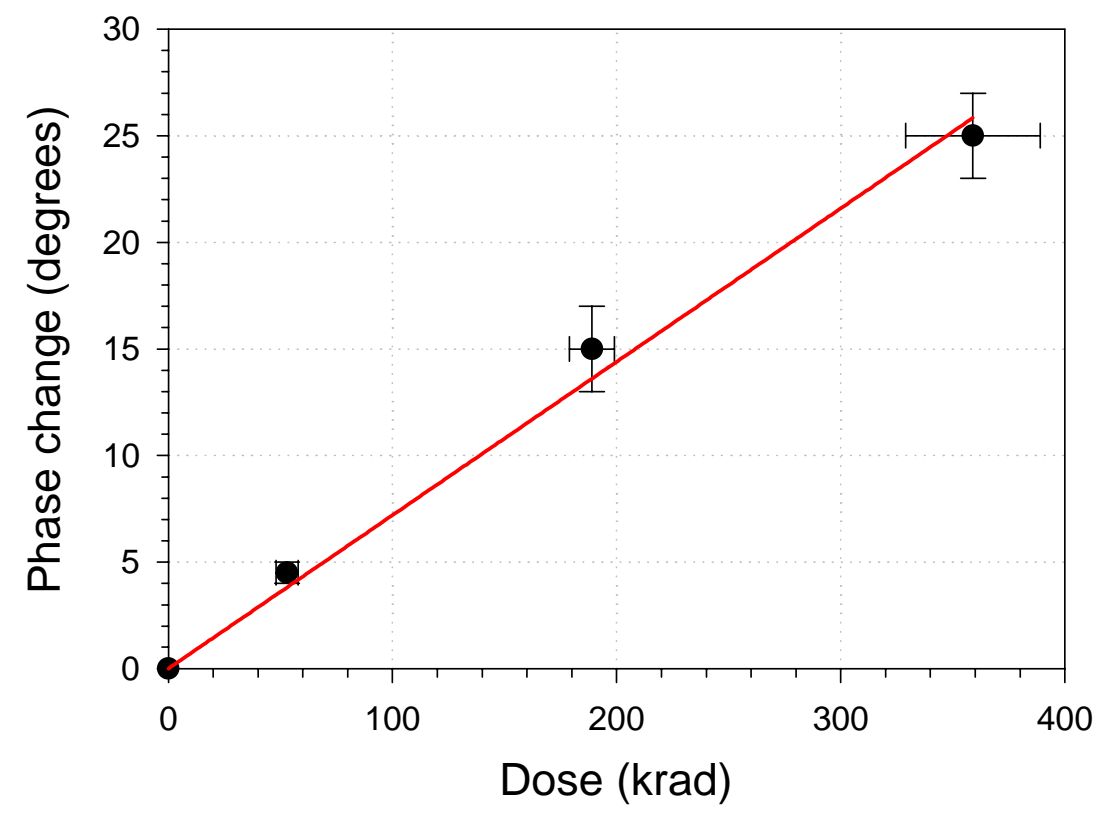

Figure 7. Change in phase versus dose for $1.0 \mathrm{~mm}$ fused silica sample. 


\subsection{Thermal Change in Index}

For a given window material, one may make a first order estimate of the change in the real index of refraction as being due to the heating associated with the absorption of energetic radiation, i.e., the thermo-optic effect. This effect has been exploited in the design of fiber-optic based interferometric dosimeters. ${ }^{3,4}$ These devices measure the phase change in one leg of a fiber interferometer due to the radiation induced heating of the fiber, analogous to the change in index of refraction measurements using our M-Z system.

A radiation pulse can transfer energy to a crystal lattice on very short time-scales. Liu $e t$ al. ${ }^{5}$ determined that the amount of time it takes for energetic electrons to transfer their energy to a silicon lattice in the form of a temperature rise is less than 10 picoseconds. Experimentally, we see a prompt index change induced by the radiation pulse (see Fig. 2). A given absorbed dose heats the sample by an amount governed by the specific heat of the sample, $C_{v}$. Table I shows the values of the specific heat and thermo-optic coefficients of materials of interest. Sapphire has separate thermo-optic coefficients for the ordinary $(\mathrm{O})$ and extraordinary $(\mathrm{X})$ crystal axes. The fractional change in index for a given dose (in $\mathrm{kGy}=\mathrm{kJ} / \mathrm{kg}=100 \mathrm{krad}$ ) is listed for comparison in the last column. From this, we see that $\mathrm{LiF}$ is the least sensitive of the three materials to thermal index changes from a given absorbed dose (due primarily to its large heat capacity). The uncertainty in the value quoted for fused silica represents the spread of reported values for various purities of fused silica.

Table I. Values of specific heat and thermo-optic coefficients of materials of interest.

\begin{tabular}{lcccc}
\multicolumn{1}{c}{ Material } & $\mathbf{n}$ & $\begin{array}{c}\boldsymbol{C}_{\boldsymbol{v}}: \\
\left.\left[\mathbf{J} / \mathbf{k g}^{\mathbf{0}} \mathbf{C}\right)\right]\end{array}$ & $\begin{array}{c}\mathbf{1} / \mathbf{n} \cdot \mathbf{\Delta} \mathbf{n} / \Delta \mathbf{T}: \\
{\left[\mathbf{C}^{-1}\right]}\end{array}$ & $\begin{array}{c}1 / \mathbf{n} \cdot \mathbf{\Delta n} / \mathbf{D o s e}: \\
{\left[\mathbf{k G y} \mathbf{y}^{-\mathbf{1}}\right]}\end{array}$ \\
\hline $\mathrm{LiF}$ & 1.3933 & 1562 & $-1.27 \times 10^{-5}$ & $-0.81 \times 10^{-5}$ \\
sapphire: $\mathrm{Al}_{2} \mathrm{O}_{3}$ & 1.7771 & 761 & $\mathrm{O}: 8.27 \times 10^{-6}$ & $1.14 \times 10^{-5}$ \\
& & & $\mathrm{X}: 8.51 \times 10^{-6}$ & $1.12 \times 10^{-5}$ \\
& & & $0.73(10) \times 10^{-5}$ & $1.0(1) \times 10^{-5}$
\end{tabular}

Our measured dose-dependent phase change for a $1.0 \mathrm{~mm}$ sample of LiF is plotted in Figure 5. The thermal model seems to agree reasonably well (within 10\%) with the observed phase changes in $\mathrm{LiF}$ (predicted $\Delta \theta /$ dose $=0.081^{\circ} / \mathrm{krad}$ versus measured $0.074(4)^{\circ} / \mathrm{krad}$ ). The thermooptic effect seems to be the dominant contribution to the change in index for LiF.

For sapphire, we observed a $\Delta \theta$ of about $27^{\circ}$ for an absorbed dose of 443(44) krad. According to the thermal picture, this dose would induce a $\Delta \theta$ of about $62(6)^{\circ}$. This is high by about a factor of 2 , however this is only one point, and difficulty measuring this quantity due to the birefringence of sapphire makes this a somewhat questionable data point.

The thermo-optic coefficient for $\mathrm{SiO}_{2}$ varies a good deal, depending on the manufacturing process. We do not know the manufacturer of our fused silica samples, and the uncertainty in the thermo-optic coefficient stated in the table reflects this. This value gives a phase change of $0.108(15)^{\circ} / \mathrm{krad}$, which is only slightly higher than our observed value, $0.072(3)^{\circ} / \mathrm{krad}$. 
It is important to note that although the thermo-optic effect is certainly responsible for a substantial fraction of the observed change in index of refraction, other factors may also add to the observed change in the real index. Any change in the imaginary index of refraction by the introduction of color centers will certainly be accompanied by a change in the real index via the Kramers-Kronig relations. This contribution may account for the observed discrepancies between our measurements and the predictions of the thermal model alone. An estimation of the Kramers-Kronig governed contribution to the change in the real index due to absorption centers requires knowledge of the energies of the absorption bands responsible for TRD. We examine the spectral nature of TRD mechanisms in section 3.

\subsection{Ultrasonic Ringing}

Another prominent feature in much of our $\mathrm{M}-\mathrm{Z}$ interferometric data is the ringing that occurs after the initial $30 \mathrm{~ns}$ radiation pulse (see Figure 2). This is caused by a thermo-elastic pressure wave created by the rapid expansion of the heated material. ${ }^{6}$ This effect has been previously used in other experiments as a means of extracting dose information, since the energy of the dose is transferred directly to the pressure-wave. ${ }^{7}$ The observed fast period of the ringing in Figure 2 is consistent with the transit time of longitudinal acoustic waves in LiF, while the lower frequencies correspond to waves along the longer axes of the window. No apparent ringing occurs in fused silica, which we believe to be due to the amorphous nature of the material.

\subsection{SPECTRALLY AND TEMPORALLY RESOLVED TRD}

In an effort to try to better understand the physics behind TRD, we set up a spectrally resolved streak system. Figure 8 shows an experimental block diagram of our system. Notice that the fiber transport system used for these experiments is somewhat similar to that used with the M-Z system. We used an Ocean Optics PX-1 xenon flash lamp as a light source, which has $5.4 \mathrm{~W}$ average output power, with a pulse duration of $5.6 \mu$ s at $1 / 3$ the pulse height. The flash lamp was coupled into the Febetron chamber via a $600-\mu \mathrm{m}$ fiber.

Light from the xenon flash is transmitted through a window sample located in front of the Febetron, and is collected by a $10 \mathrm{X}$ microscope objective and sent back to the screen room via a $200-\mu \mathrm{m}$-diameter fiber. The transmitted light is then inserted into a $0.5 \mathrm{~m}$ Jarrel-Ash / Fisher Scientific monochromator with a 150 lines/mm grating that disperses the light spectrum spatially over the photocathode of a Hamamatsu streak camera. The grating diffracts a 400- to 700-nm spread on the streak camera. This spectral range may be accurately calibrated using a set of interference filters.

The monochromator is mounted on a custom-built axis alignment mount in order to locate the image plane of the input fiber onto the input optics of the streak camera. The streak camera is a Hamamatsu Temporal Disperser model C1587 with an M1953 slow streak module. Light is coupled in via a model A1975 3:1 reducing snout in order to obtain the desired spectral range. The 3:1 coupler has a limited transmission range of $400-850 \mathrm{~nm}$. The streak image is recorded using a Peltier-cooled CCD camera model C3140 controlled by a GPIB interface unit model C3366. Streak images are recorded with 12-bit resolution, and the streak-time is set to $600 \mathrm{~ns}$. The spectral and temporal resolutions of our system are limited by the size of the input fiber, and are approximately $7.6 \mathrm{~nm}$, and $16 \mathrm{~ns}$ respectively. 

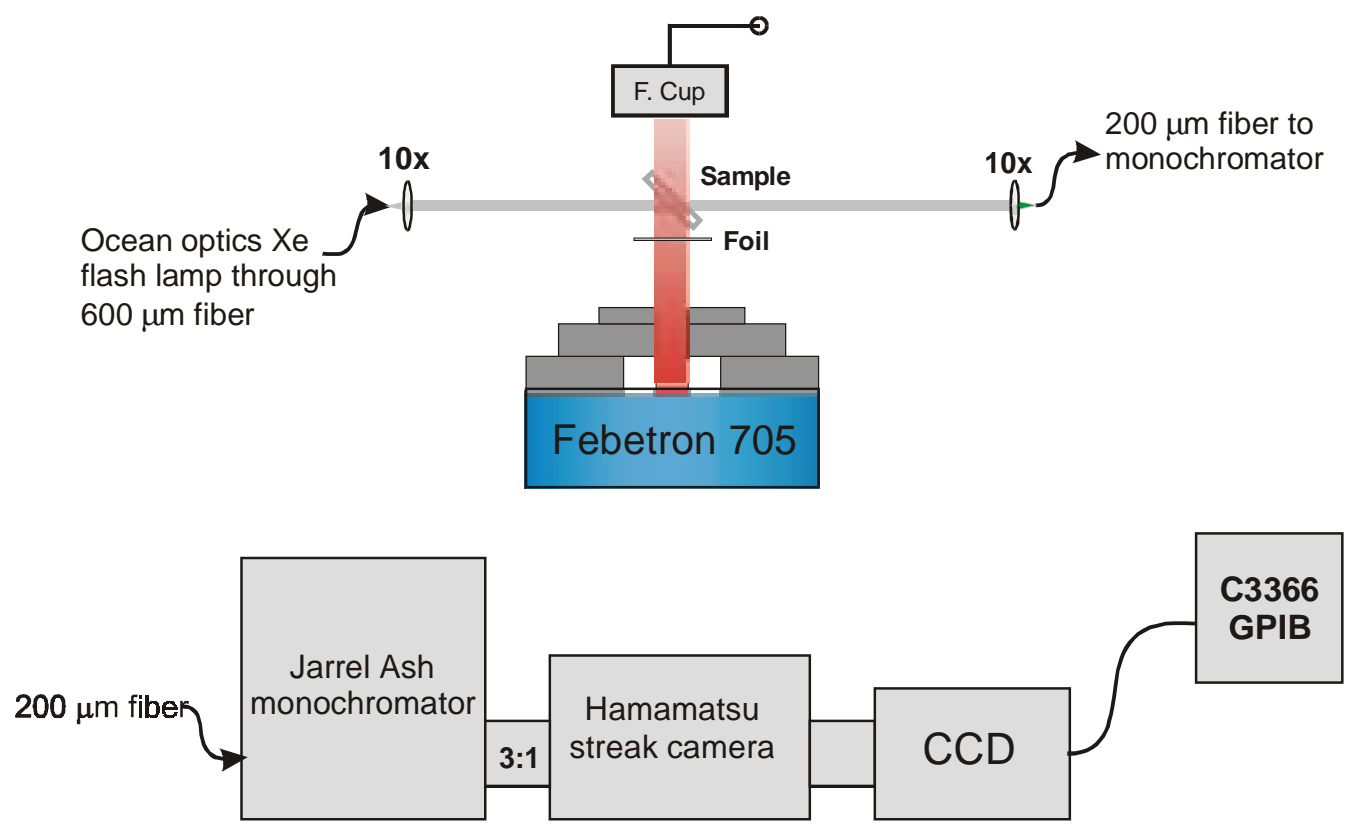

Figure 8. Spectral streak apparatus.

Three streak images of a xenon-flash are recorded and averaged to be used to normalize test data. We also record a separate streak of the radiation-induced luminescence that is composed predominantly of Cerenkov light as well as radioluminescence. Radioluminescence is caused by the excitation of color centers, and contains information about the type and number of color centers and lattice defects present in an irradiated specimen. ${ }^{8}$ The luminescence streak is subtracted from our raw data, and the result is normalized by the Xe-flash image. The resulting image ideally has pixel values ranging from 0 to 1 , representing the transmittance of the irradiated window as a function of wavelength and time. We normalize this image to 20,000 to convert to a compatible TIFF format for file storage. In the reported figures, a value of 20,000 represents $100 \%$ transmission.

Figure 9 and Figure 10 show the results of TRD spectral streak measurements for $\mathrm{LiF}$, and Figure 11 and Figure 12 show the results for sapphire. Figure 13 shows time slices of the LiF spectral streak shown in Figures 11 and 12 at various times. LiF shows some preferential absorption of blue light. This suggests that one way to mitigate the loss of signal in an experiment utilizing $\mathrm{LiF}$ in a radiation environment is to use infrared light. Presumably, the longer the wavelength used, the less pronounced the TRD will be. Further measurements would be needed to affirm this assertion. 


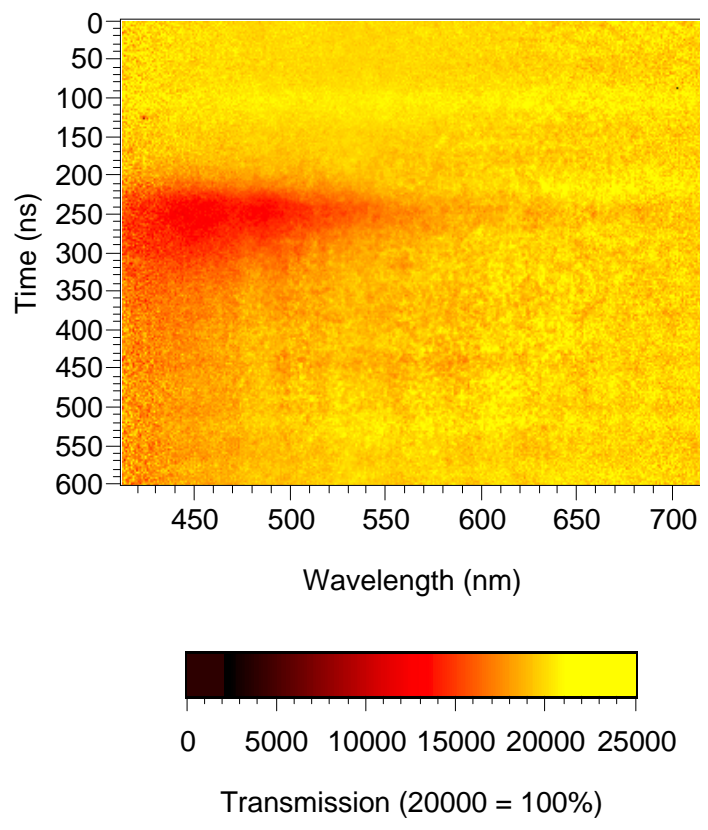

Figure 9. Spectral streak of TRD in a $1.0 \mathrm{~mm}$ sample of $\mathrm{LiF}$ for an absorbed dose of $425 \mathrm{krad}$. The minimum transmittance is about 0.85 at $542 \mathrm{~nm}$. A signal of 20,000 corresponds to $100 \%$ transmission.

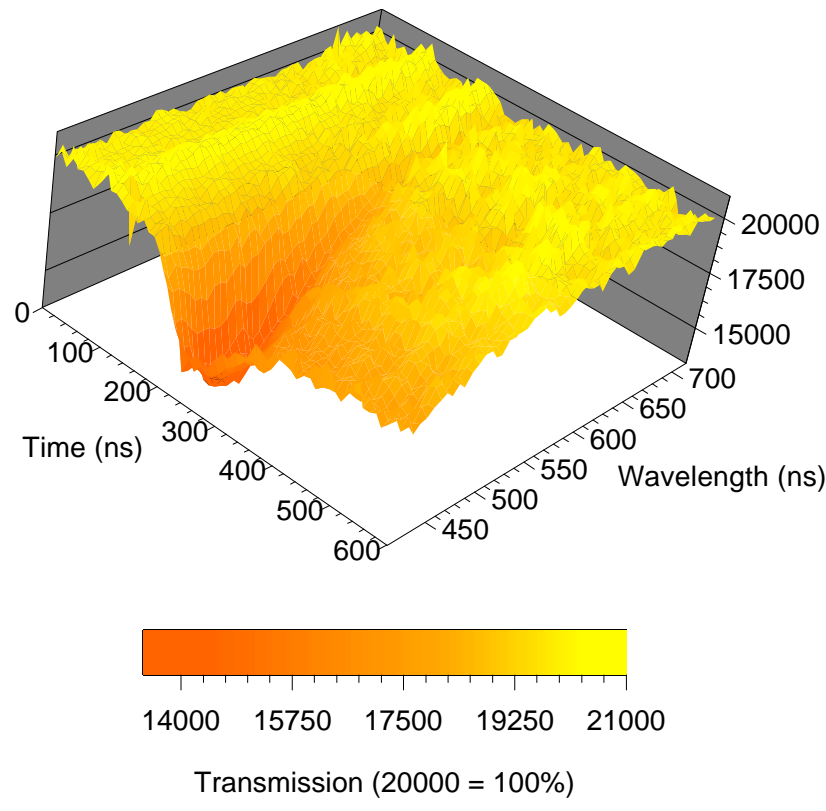

Figure 10. 3-D plot of Figure 9. A signal of 20,000 implies 100\% transmission. 

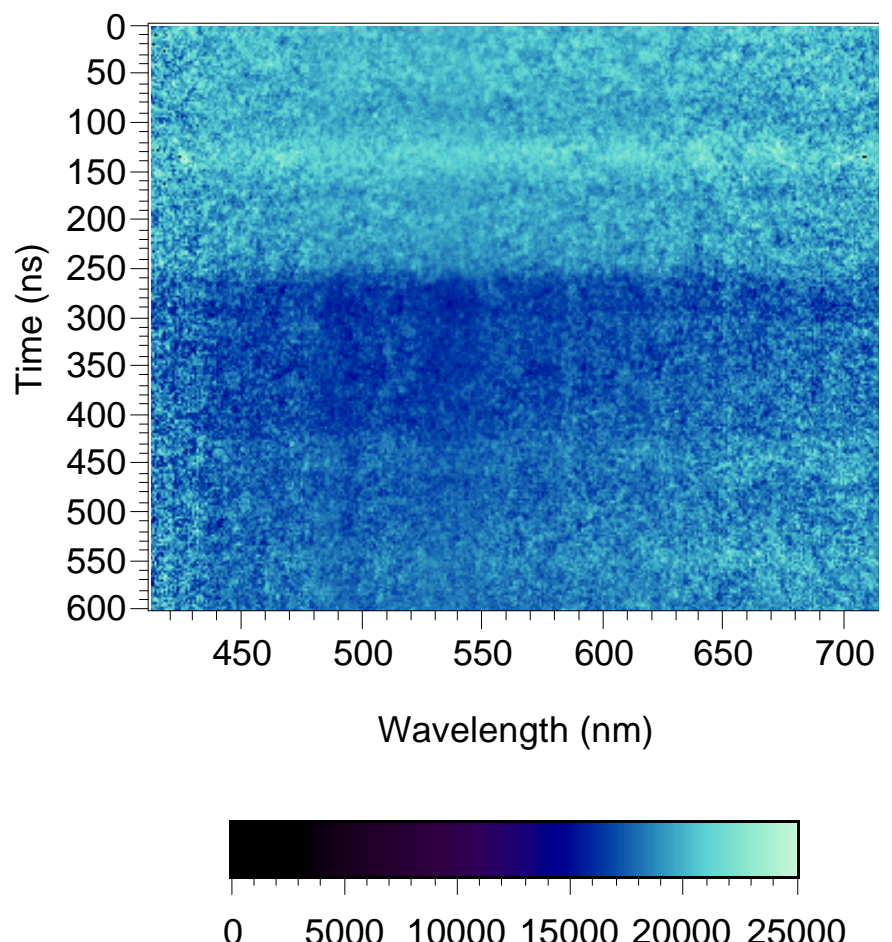

Transmission $(20000=100 \%)$

Figure 11. Spectral streak of TRD in a $1.0 \mathrm{~mm}$ sample of sapphire for an absorbed dose of $535 \mathrm{krad}$. The minimum transmittance is about 0.80 at $542 \mathrm{~nm}$. A signal of 20,000 corresponds to $100 \%$ transmission.
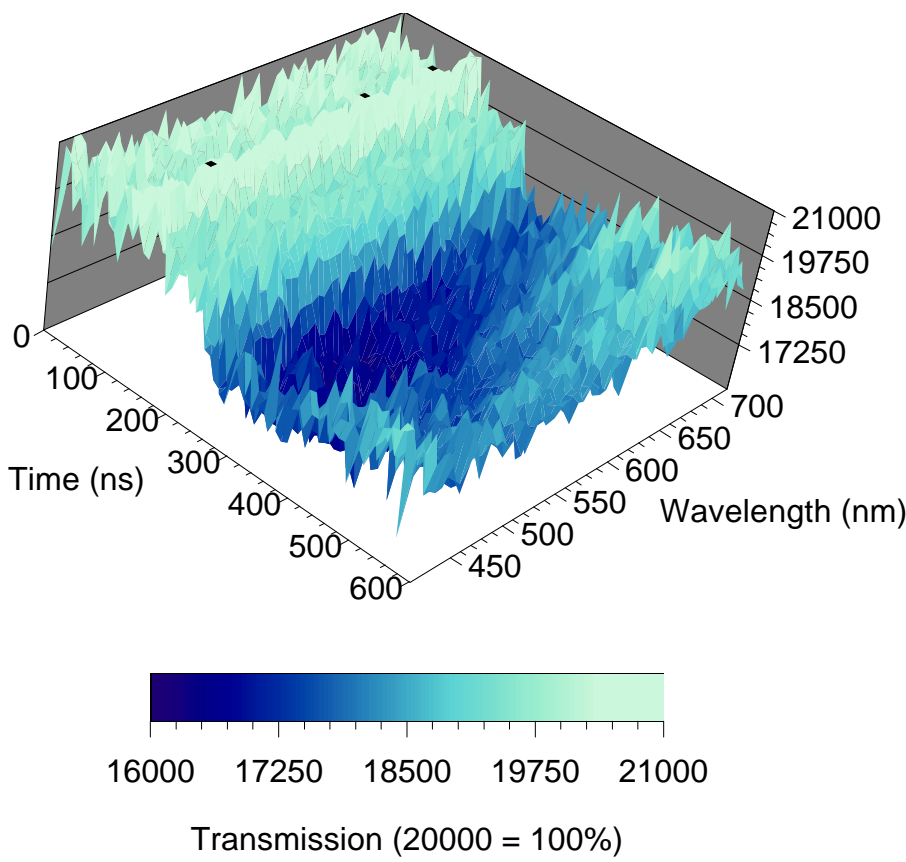

Figure 12. 3-D plot of Figure 11. A signal of 20,000 implies 100\% transmission. 


\subsection{Discussion of Spectral Streak Results, Color Center, and Colloid Formation}

\subsubsection{Lithium Fluoride (LiF)}

Lithium fluoride's $F, F_{2}, F_{2}{ }^{+}$, and $F_{3}{ }^{+}$color centers absorb light at 250, 444, 625, and $448 \mathrm{~nm}$ respectively. ${ }^{9}$ The $F_{2}$ and $F_{3}{ }^{+}$color centers make up the so-called " $M$ " absorption band, and re-emit at 670 and $539 \mathrm{~nm}$ respectively. ${ }^{10}$ There are several weaker visible absorption bands due to more complex aggregate centers called " $R$ " centers. Irradiated LiF also produces luminescence due to recombination of excitons. This luminescence peaks in the ultraviolet, and has a broad structure spanning $270-390 \mathrm{~nm} .{ }^{11}$ The broad $F_{2}{ }^{-}$absorption band $(0.9$ to $1.0 \mu \mathrm{m})$, and its associated emission band (1.1-1.3 $\mu \mathrm{m})$ have been exploited to create LiF color-center lasers, such as the novel "superbroadband" $\mathrm{LiF}: F_{2}{ }^{-}$laser. ${ }^{12}$ Lasers of the $F_{2}{ }^{+}$variety also exist, with the somewhat short-lived ( 12 hour "half life") $F_{2}{ }^{+}$color centers being stabilized by the addition of impurities such as $\mathrm{LiOH}, \mathrm{Li}_{2} \mathrm{O}$, and $\mathrm{MgF}_{2}{ }^{13}$

The observed increase in transient absorption with decreasing wavelength in LiF does not seem to relate in an obvious way to the previously listed absorption spectrum of simple color centers and aggregates. One possible contributor to the TRD process may be the transient formation of larger aggregates such as metallic colloids. These colloids are comprised of large $F$-center clusters, and have unique absorption characteristics. Usually, colloid formation is not observed at room temperature due to the low mobility of $F$-centers in the bulk material, however at the enormous dose rates our samples are subjected to, radiation-induced mobility may enhance the colloid formation process.

Hodgson $e t$ al. showed that there is a radiation-induced $F$-center diffusion rate that depends directly on dose rate. ${ }^{14}$ This work was done with $\mathrm{NaCl}$ crystals, with maximum dose rates of about $10^{4} \mathrm{rad} / \mathrm{s}$, and appreciable dose-rate dependent effects were observed. By comparison, the dose rates of our experiments may exceed $1 \times 10^{13} \mathrm{rad} / \mathrm{s}$, nine orders of magnitude higher. Whether or not one may extrapolate the results of Hodgson by nine orders of magnitude, one may at least assume that the mobility of the $F$-centers produced under Febetron irradiation is quite high. According to Hughes and Jain, ${ }^{15}$ "If alkali halides are irradiated at temperatures where $F$-centers are known to be mobile enough to form colloids, then growth of colloids takes on a very significant role." Although our samples are at room temperature, the $F$-centers are highly mobile during irradiation, and it is reasonable to assume that some colloid formation takes place during a radiation pulse. Hughes and Jain continue, "Once nucleated, a colloid is an effective sink for mobile $F$-centres and growth of the colloids takes place in competition with the dynamic $F$-centre-interstitial recombination which at room temperature and below restricts the saturation level of irradiation-induced defects..." Since we have observed saturation behavior in our characterization of TRD, we might also attribute this phenomenon to the formation of colloids.

Lithium colloids imbedded in a LiF crystal lattice have a broad absorption band centered at about $450 \mathrm{~nm}$ that shifts slightly higher in wavelength, and narrows considerably with an increase in colloid size. Siefert et al. used Mie scattering theory to calculate the extinction coefficients for metallic colloids imbedded in alkali halide crystals. ${ }^{16}$ 
Figure 13 shows a plot of the transmittance of a 1.0 -mm-thick LiF sample versus wavelength for several sizes of single radius round colloids using extinction coefficients predicted by Siefert $e t$ al. Figure 14 shows TRD profiles for various times during and just after the radiation pulse. It is interesting to note that the absorption band in Figure 14 seems to shift toward lower wavelengths, and to broaden after the radiation pulse. This is consistent with colloids shrinking in size after formation, perhaps being "frozen" back into the crystal lattice. Siefert's calculated absorption line-shape for 1-nm-diameter colloids is suggestive of our TRD profile at maximum darkening (denoted $t=244$ ns on Figure 14).

Comparison of the profiles in Figure 14 with the long term (several minutes to days after irradiation) transmission profiles in Figure 13 shows that the observed transient darkening absorption, with a half-width wider than $100 \mathrm{~nm}$, is far broader than the $\sim 35 \mathrm{~nm}$ widths of the $F_{2}$-centers. Also, just after irradiation, there is a decrease in the $F_{2}$ population, which takes several hours to replenish itself from conversion of other types of color center. Transient production of colloids during a radiation pulse seems to be a more likely candidate for a source of TRD during a radiation pulse.

\subsubsection{Sapphire $\left(\mathrm{Al}_{2} \mathrm{O}_{3}\right)$}

In sapphire, an $F$-center is comprised of an oxygen vacancy that has captured 2 electrons. $F$-centers absorb light at $204 \mathrm{~nm}$, and emit at $410 \mathrm{~nm}$. $F^{+}$-centers absorb light at both 228 and $257 \mathrm{~nm}$, and emit at $330 \mathrm{~nm} . F_{2}$ color centers have four absorption bands ranging from 299 to $373 \mathrm{~nm}$. The emission bands in sapphire are formed by pre-existing defects, and not defects created during irradiation, hence the emission spectrum depends on the pre-irradiation history of a sample. $^{11}$

Since the color center absorption bands in sapphire are in the uv, and since the observed darkening is fairly uniform from 400 to $700 \mathrm{~nm}$, we suspect that darkening mechanisms other than simple color centers may be at work. Tiny (tenths of $\mathrm{nm}$ ) aluminum colloids have been predicted to form in irradiated sapphire samples immersed in an external electric field. It is believed that these colloids contribute to radiation-induced electrical degradation of insulating sapphire in nuclear reactor components. A wide absorption band for aluminum colloids imbedded in sapphire is predicted at a center wavelength of between 220 and $270 \mathrm{~nm} .^{17}$

We modified our spectral steak system to extend the range towards lower wavelengths to try to look for colloidal absorption. Unfortunately, the sensitivity of our streak camera's photo-cathode drops off by more than a decade for each $50 \mathrm{~nm}$ increment below $400 \mathrm{~nm}$. Since our observed darkening signal to noise ratio is only about $4: 1$ at $400 \mathrm{~nm}$, we were only able to extend the range of the spectrometer measurement down to $350 \mathrm{~nm}$. The proposed colloid absorption band was far enough below our experimental range that we were unable to verify its presence. 


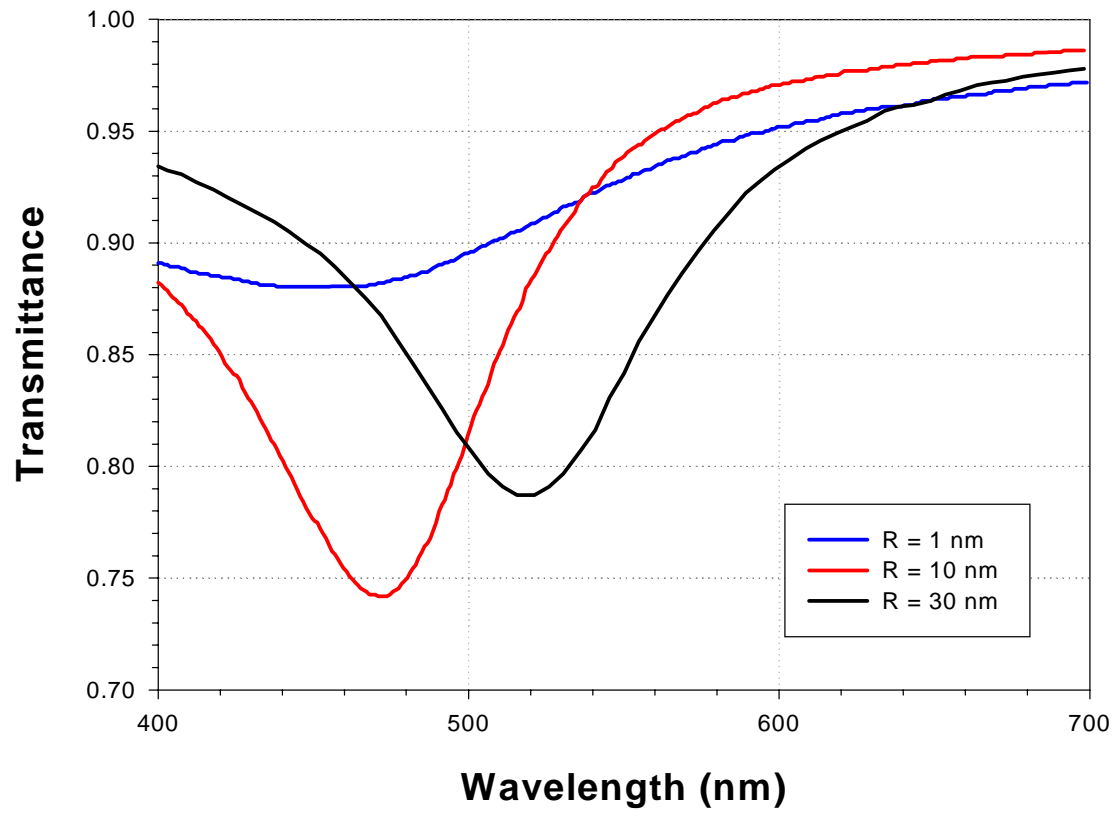

Figure 13. Extinction coefficients for Li colloids of varying size within $\mathrm{LiF}$ crystal calculated by Seifert et al. The absorption profile for 1-nm radius lithium colloids is suggestive of the absorption profiles in Figure 14.

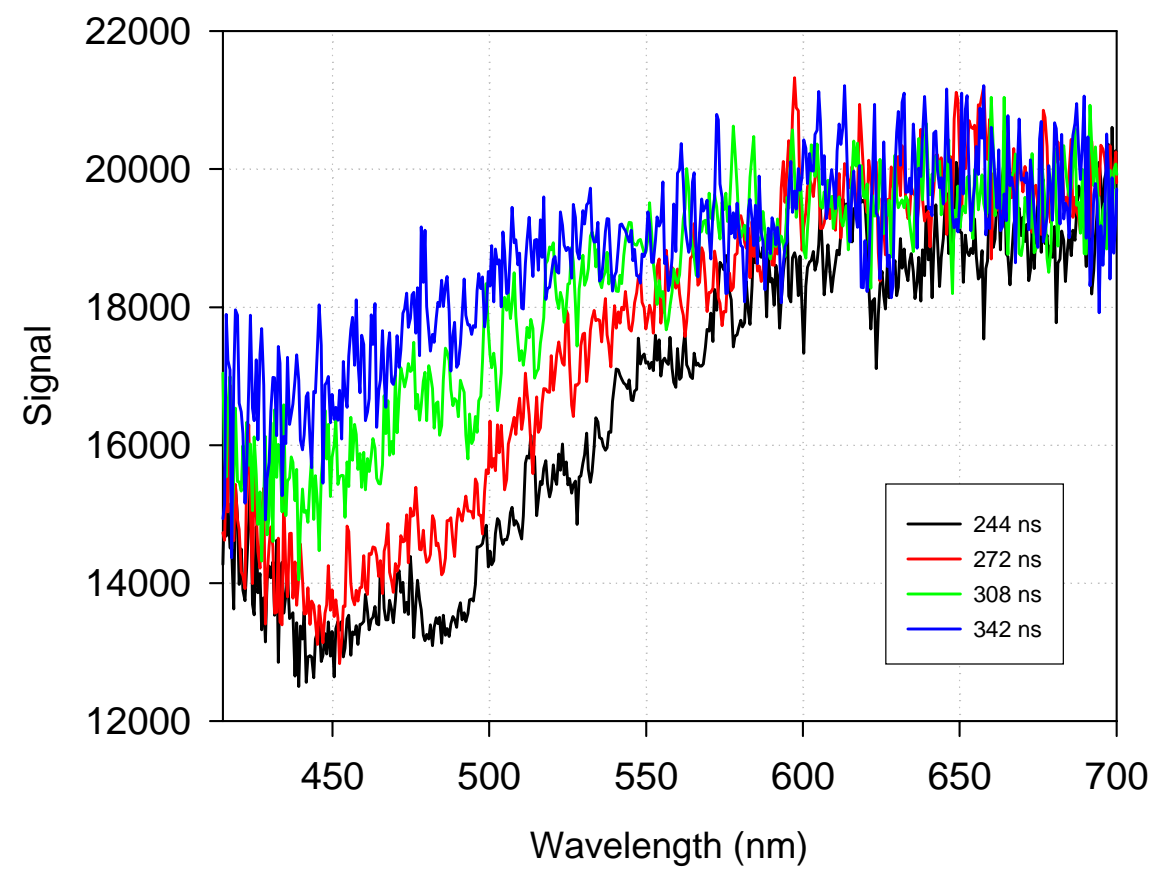

Figure 14. TRD time slices in LiF. A signal of 20,000 implies $100 \%$ transmission. 


\subsubsection{Fused Silica $\left(\mathrm{SiO}_{2}\right)$}

Fused silica has color centers formed at oxygen vacancies that absorb light at $215 \mathrm{~nm}$. The dominant radiation induced light produced in fused silica is Cerenkov light, but radioluminescence between 200 and $300 \mathrm{~nm}$ has been observed. ${ }^{18}$ Fused silica is so radiation resistant that we could not directly observe darkening in a $1.0 \mathrm{~mm}$ bulk sample. Also, the absorption and emission responses are sufficiently far into the uv that our system was not capable of observing either of these phenomena.

\subsection{CONCLUSIONS}

Our results indicate that the radiation-induced change in the real component of the index of refraction is small, with $\delta \mathrm{n} / \mathrm{n} \sim 10^{-5} / \mathrm{kGy}$. This is the right order of magnitude to be attributed predominantly to a heating effect. The current data for sapphire and fused silica suggest that there may be other contributions to TRD, but as a first-order estimate the thermo-optic picture provides excellent estimates. We have seen the onset of saturation of TRD at several hundred $\mathrm{krad}$ in LiF and sapphire. Saturation in radiation darkening has been observed in fiber optics and various other materials. ${ }^{19}$ The maximum darkening observed was $29 \%$ for a $2.0-\mathrm{mm}$-thick sample of $\mathrm{LiF}$, and $18 \%$ for a $1.0 \mathrm{~mm}$ sample of sapphire. These values pertain only to the specific windows characterized in our experiments. TRD in windows with different impurity levels will probably saturate at different incident dose levels.

Currently, the absorption processes that contribute to TRD at a given wavelength are not fully understood. The long term accumulated radiation damage to a crystal manifests itself in the presence of color centers. The prompt, short-term kinetics of color center formation has been examined by Lisitsyna and others. ${ }^{2}$ They have not, however, identified the mechanisms at play during an intense, short radiation pulse. Transient formation of colloids may account for the prompt, severe darkening that is concurrent with a radiation pulse.

In order to mitigate the effects of TRD in VISAR experiments that use LiF windows, or in other experiments that take place in harsh radiation environments, one could make use of longer wavelength probe light. Photo-bleaching of problematic color centers is a also a possible remedy, but only for long term degradation of transmission. The transient darkening component cannot in any obvious way be lessened by bleaching with light. Several experiments were performed with additional light present in an attempt to prohibit color center formation, however none of these experiments were successful. Operating at elevated temperatures helps inhibit long-term absorption due to color centers, but may make matters worse for a transient phenomenon by increasing color center mobility. 


\section{REFERENCES}

1. W. Gellermann, et al., "Formation, optical properties and laser operation of $F_{2}{ }^{-}$-centers in LiF", J. Appl. Phys. 61, 1297 (1987).

2. L.A. Lisitsyna, "Laws governing the creation of electronic color centers in LiF crystals acted on by pulsed irradiation", Russ. Phys. J. 39, 1050-66 (1996).

3. F. Barone et al., "Detection of $\mathrm{x}$ rays with a fiber-optic interferometric sensor", Applied Optics 32, 1229 (1993).

4. J.J. Suter, J.C. Poret, and M. Rosen, "Fiber optic ionizing radiation detector", IEEE Trans. Nucl. Sci. Vol. 39, No. 4, 674-9 (1992).

5. J. M. Liu, R. Yen, H. Kurz, and N. Bloembergen, "Phase transformation on and charged particle emission from a silicon crystal surface, induced by picosecond laser pulses.", Appl. Phys. Lett 39, 755 (1981).

6. N. A. Baily, "A review of the processes by which ultrasound is generated through the interaction of ionizing radiation and irradiated materials: Some possible applications", Med. Phys 19, 525 (1992).

7. F. C. Perry, "Thermoelastic dosimetry of relativistic electron beams" Appl. Phys. Lett. 17 408 (1970).

8. A. Morono, E. R. Hodgson, "Radioluminescence problems for diagnostic windows", J. Nucl. Matter. 224 216-21 (1995).

9. G. Baldacchini et al., "Colour centres induced in LiF by low-energy electrons" J. Phys.: Condens. Matter 10, 857-67 (1998).

10. G. Baldacchini et al., "Optical bands of $F_{2}$ and $F_{3}{ }^{+}$-centers in LiF", J. Phys. Chem. Solids 61, 21-26 (2000).

11. V.A. Skuratov, "Luminescence of $\mathrm{LiF}$ and $\alpha-\mathrm{Al}_{2} \mathrm{O}_{3}$ crystals under high density excitation", Nucl. Instr. And Meth. B 146 385-92 (1998).

12. T. Tasoltan et al., "Multiline, superbroadband and sun-color oscillation of a $\mathrm{LiF}: \mathrm{F}_{2}{ }^{-}$colorcenter laser", Applied Optics 36, 2515-2522 (1997).

13. A. Yu. Dergachev, S.B. Mirov, "Efficient room temperature LiF:F2+** color center laser tunable in 820-1210 nm range", Opt. Comm. 147,107-111(1998).

14. E.R. Hodgson, A. Delgado, and J.L. Alvarez Rivas, "An apparent radiation induced $F$ centre diffusion process in $\mathrm{NaCl}$ at and above room temperature", J. Phys. C, 14 337-45 (1981).

15. A.E. Hughes and S.C. Jain, "Metal colloids in ionic crystals", Advances in Physics, 28, 717-828 (1979).

16. N. Seifert et al., "The influence of defects and defect clusters on alkali atom desorption stimulated by low energy electron bombardment of alkali halides", Nucl. Instr. And Meth. In Phys. Res. B 84, 77-88 (1994).

17. A. Moroño and E.R. Hodgson, "Enhanced oxygen vacancy aggregation and colloid production in $\mathrm{Al}_{2} \mathrm{O}_{3}$ ", J. Nucl. Mater. 250 156-63 (1997).

18. A. Moroño and E.R. Hodgson, "Radiation induced optical absorption and radioluminescence in electron irradiated $\mathrm{SiO}_{2}$ ", J. Nucl. Mater. 258-63 1889-92 (1998).

19. J. H. Schulmann and W. D. Compton, Color Centers in Solids, Pergamon 209 (1962). 


\section{DISTRIBUTION}

U.S. Department of Energy

National Nuclear Security Administration

Nevada Operations Office

Technical Information Resource Center

P.O. Box 98518

Las Vegas, NV 89193-8518

U.S. Department of Energy

Office of Scientific and Technical Information

P.O. Box 62

Oak Ridge, TN 37831-0062

U.S. Department of Energy

National Nuclear Security Administration

Nevada Operations Office Public Reading Facility

NLV 040

P.O. Box 98521

Las Vegas, NV 89193-8521

James R. Asay, SNL M/S 1181

Clint A. Hall, SNL M/S 1181

Marcus D. Knudson, SNL M/S 1181

Phillip W. Watts, SNL M/S 1192 